Tozer, D. C., C. Myles Falconer, A. M. Bracey, E. E. Gnass Giese, G. J. Niemi, R. W. Howe, T. M. Gehring, and C. J. Norment. 2017. Influence of call broadcast timing within point counts and survey duration on detection probability of marsh breeding birds. Avian Conservation and Ecology 12(2):8. https://doi.org/10.5751/ACE-01063-120208

Copyright (C) 2017 by the author(s). Published here under license by the Resilience Alliance.

Research Paper

\title{
Influence of call broadcast timing within point counts and survey duration on detection probability of marsh breeding birds
}

\author{
Douglas C. Tozer ${ }^{1}$, C. Myles Falconer ${ }^{1}$, Annie M. Bracey ${ }^{2}$, Erin E. Gnass Giese ${ }^{3}$, Gerald J. Niemi ${ }^{2,4}$, Robert W. Howe ${ }^{3,5}$, Thomas M. \\ Gehring $^{6}$ and Christopher J. Norment ${ }^{7}$ \\ ${ }^{1}$ Bird Studies Canada, ${ }^{2}$ Natural Resources Research Institute, University of Minnesota Duluth, ${ }^{3}$ Cofrin Center for Biodiversity, \\ University of Wisconsin-Green Bay, ${ }^{4}$ Department of Biology, University of Minnesota Duluth, ${ }^{5}$ Department of Natural and Applied \\ Sciences, University of Wisconsin-Green Bay, ${ }^{6}$ Department of Biology and Institute for Great Lakes Research, Central Michigan \\ University, ${ }^{7}$ Department of Environmental Science and Ecology, The College at Brockport, State University of New York
}

\begin{abstract}
The Standardized North American Marsh Bird Monitoring Protocol recommends point counts consisting of a 5-min passive observation period, meant to be free of broadcast bias, followed by call broadcasts to entice elusive species to reveal their presence. Prior to this protocol, some monitoring programs used point counts with broadcasts during the first 5 min of 10 -min counts, and have since used 15-min counts with an initial 5-min passive period $\left(\mathrm{P}_{1}\right)$ followed by $5 \mathrm{~min}$ of broadcasts $(\mathrm{B})$ and a second 5-min passive period $\left(\mathrm{P}_{2}\right)$ to ensure consistency across years and programs. Influence of timing of broadcasts within point counts and point count duration, however, have rarely been assessed. Using data from 23,973 broadcast-assisted 15-min point counts conducted throughout the Great Lakes-St. Lawrence region between 2008 and 2016 by Bird Studies Canada's Marsh Monitoring Program and Central Michigan University's Great Lakes Coastal Wetland Monitoring Program, we estimated detection probabilities of individuals for 14 marsh breeding bird species during $\mathrm{P}_{1} \mathrm{~B}$ compared to $\mathrm{BP}_{2}, \mathrm{P}_{1}$ compared to $\mathrm{P}_{2}$, and $\mathrm{P}_{1} \mathrm{~B}$ compared to $\mathrm{P}_{1} \mathrm{BP}_{2}$. For six broadcast species and American Bittern (Botaurus lentiginosus), we found no significant difference in detection during $\mathrm{P}_{1} \mathrm{~B}$ compared to $\mathrm{BP}_{2}$, and no significant difference in four of the same seven species during $\mathrm{P}_{1}$ compared to $\mathrm{P}_{2}$. We observed small but significant differences in detection for 7 of 14 species during $\mathrm{P}_{1} \mathrm{~B}$ compared to $\mathrm{P}_{1} \mathrm{BP}_{2}$. We conclude that differences in timing of broadcasts causes no bias based on counts from entire 10 minute surveys, although $\mathrm{P}_{1} \mathrm{~B}$ should be favored over $\mathrm{BP}_{2}$ because the same amount of effort in $\mathrm{P}_{1} \mathrm{~B}$ avoids broadcast bias in all broadcast species, and 10-min surveys are superior to 15-min surveys because modest gains in detection of some species does not warrant the additional effort. We recommend point counts consisting of $5 \mathrm{~min}$ of passive observation followed by broadcasts, consistent with the standardized marsh bird protocol, for surveying marsh breeding birds.
\end{abstract}

\section{Influence du moment de diffusion d'enregistrements de chant pendant un point d'écoute et de la durée du point d'écoute sur la probabilité de détection d'oiseaux de marais nicheurs}

RÉSUMÉ. Le Protocole normalisé de surveillance des oiseaux de marais d'Amérique du Nord recommande d'effectuer des points d'écoute consistant en une période d'écoute passive de 5 minutes, pour qu'il n'y ait aucun biais associé à la diffusion d'enregistrements de chant, suivie de diffusions d'enregistrements destinées à inciter les espèces discrètes à révéler leur présence. Avant l'instauration de ce protocole, certains programmes de surveillance préconisaient des points d'écoute comprenant la diffusion d'enregistrements durant les 5 premières minutes d'une période d'écoute de 10 minutes, et avaient ensuite privilégié des points d'écoute de 15 minutes, consistant en une période initiale d'écoute passive de 5 minutes (P1), suivie de 5 minutes de diffusion d'enregistrements (B), puis d'une seconde période d'écoute passive de 5 minutes (P2) afin d'assurer une constance entre les années et les programmes. Toutefois, l'influence du moment de la diffusion d'enregistrements de chant pendant un point d'écoute et celle de la durée du point d'écoute ont rarement été évaluées. Au moyen des résultats de 23973 points d'écoute de 15 minutes, qui comprenaient de la diffusion d'enregistrements et ont été réalisés dans la région des Grands Lacs-Saint-Laurent entre 2008 et 2016 dans le cadre du Programme de surveillance des marais d'Études d'Oiseaux Canada et du Great Lakes Coastal Wetland Monitoring Program de la Central Michigan University, nous avons estimé la probabilité de détection d'individus appartenant à 14 espèces d'oiseaux de marais nicheurs durant $\mathrm{P} 1 \mathrm{~B}$ comparativement à $\mathrm{BP} 2$, $\mathrm{P} 1$ comparée à $\mathrm{P} 2$, et $\mathrm{P} 1 \mathrm{~B}$ comparée à P1BP2. Pour 6 espèces pour lesquelles des enregistrements de chant ont été diffusés et le Butor d'Amérique (Botaurus lentiginosus), nous n'avons pas trouvé de différence de détection durant $\mathrm{P} 1 \mathrm{~B}$ comparée à BP2, ni de différence significative pour 4 des mêmes 7 espèces durant $\mathrm{P} 1$ comparée à $\mathrm{P} 2$. Nous avons observé des différences de détection petites mais significatives pour 7 des 14 espèces durant $\mathrm{P} 1 \mathrm{~B}$ comparée à $\mathrm{P} 1 \mathrm{BP} 2$. Nous arrivons à la conclusion que le moment choisi pour diffuser les enregistrements de chant pendant un point d'écoute ne cause pas de biais d'après les dénombrements obtenus dans un point d'écoute de 10 minutes, même si P1B devrait être privilégiée à BP2 parce que le même effort dans P1B permet d'éviter le biais de diffusion d'enregistrements pour toutes les espèces pour lesquelles on a diffusé des enregistrements, et que les points d'écoute de 10 minutes sont préférables à ceux de 15 minutes,

Address of Correspondent: Douglas C. Tozer, P.O. Box 160, (Courier: 115 Front Street), Port Rowan, ON, Canada N0E1M0, dtozer@birdscanada.org 
car le gain modeste dans la détection de certaines espèces réalisé avec ces derniers ne vaut pas l'effort additionnel. Pour dénombrer les oiseaux de marais nicheurs, nous recommandons d'effectuer des dénombrements par point d'écoute consistant en 5 minutes d'écoute passive suivie de diffusions d'enregistrements, conformément au protocole normalisé des oiseaux de marais.

Key Words: audio lures; Bird Studies Canada’s Marsh Monitoring Program; call broadcasts; Central Michigan University’s Great Lakes Coastal Wetland Monitoring Program; Standardized North American Marsh Bird Monitoring Protocol

\section{INTRODUCTION}

Considerable advances have been made in developing scientifically rigorous, yet cost-effective field survey protocols for monitoring elusive marsh bird species. In North America, the outcome has been the Standardized North American Marsh Bird Monitoring Protocol (hereafter, standardized marsh bird protocol; Conway 2011). The standardized marsh bird protocol was developed because in many regions other broad-scale monitoring programs have failed to provide adequate data to answer important questions about elusive and poorly detected marsh breeding bird species. For instance, long-term trends of marsh breeding bird species in the southern Great Lakes basin are more precise and useful for management when based on data collected by the standardized marsh bird protocol (Tozer 2013, 2016) compared with trends based on data from the North American Breeding Bird Survey (Environment Canada 2014, Sauer et al. 2014). The standardized marsh bird protocol is more useful because it (1) uses standardized call broadcasts of elusive species during each survey, (2) involves repeated surveys per year at each survey point, and (3) requires survey points occur within suitable marsh bird habitat. This generates higher detection probabilities for elusive species and greater statistical power, and thus, the standardized marsh bird protocol has been adopted by various marsh bird monitoring programs throughout North America (e.g., Seamans et al. 2013, Conway and Seamans 2016, Tozer 2016, Correll et al. 2017).

The standardized marsh bird protocol requires point counts consisting of an initial 5-min passive observation period (with no call broadcasts) followed by a variable number of 1-min periods during which calls of elusive species are broadcast to entice individuals to reveal their presence, predominantly by responding vocally. Data from the initial 5-min passive observation period allow for analyses free of broadcast bias (Conway 2011). Broadcast bias includes drawing broadcast species closer to the observer before they become available for detection, i.e., before they vocalize or become visible, and increased difficulty in hearing nonbroadcast species during the broadcast period (Conway and Gibbs 2005). These sources of bias can be problematic when determining densities and associated population sizes (e.g., Wiest et al. 2016).

Although influence of the timing of call broadcasts within point counts has rarely been assessed, a growing number of studies have used a suite of methods to compare detections of marsh breeding birds during initial passive observation periods and subsequent broadcast periods, and have found significant increases in detections for nearly all species (reviewed in Conway and Gibbs 2011). Only two studies we are aware of have reported detection rates during initial passive observation periods as well as subsequent broadcast and final passive observation periods; both found increases during broadcasts and reductions during subsequent passive observation (Lor and Malecki 2002,
DesRochers et al. 2008). However, these studies reported raw counts for each period or percent changes in raw counts between subsequent periods. Simultaneously estimating abundance and detection probability using recent advances in hierarchical modeling to account for influential covariates and imperfect detection (reviewed in Dénes et al. 2015) during various periods and combinations of periods within broadcast-assisted point counts has yet to be reported. Such an analysis is important because conducting passive observations at the end of the point count may cause bias via continued heightened activity of birds due to previous broadcasts. Conducting the passive observation period at the end of the point count might jeopardize the unbiased information that the passive period is intended to gather in the first place. By contrast, if most individuals are detected during broadcasts, then results based on the broadcast period combined with either prior or subsequent passive observation periods might be similar regardless of broadcast timing.

The influence of call broadcast timing within point counts is especially relevant to multiple broad-scale regional marsh bird monitoring programs. Bird Studies Canada's Marsh Monitoring Program has surveyed hundreds of points throughout the Great Lakes-St. Lawrence region annually since 1995 (Fig. 1), which has provided for numerous useful analyses ranging from population trends to habitat associations (e.g., Timmermans et al. 2008, Tozer 2013, 2016). From 1995 to 2007, the MMP conducted 10-min point counts consisting of $5 \mathrm{~min}$ of broadcasts followed by $5 \mathrm{~min}$ of passive observation. Since 2008, the Marsh Monitoring Program incorporated the standardized marsh bird protocol by conducting 15 -min point counts consisting of an initial 5-min passive period, followed by $5 \mathrm{~min}$ of broadcasts, and a second 5-min passive period. This 15 -min pattern was adopted because 1995-2007 data could be combined during analysis with a subset of post-2007 data (the last two 5-min periods), plus a subset consistent with the standardized marsh bird protocol was also possible (the first two 5-min periods). The longer 15-min pattern was also presumed to achieve superior detection of elusive species, a bonus for boosting statistical power during trend and habitat analyses. For these reasons, the 15 -min point count pattern was also recommended for use by the Great Lakes Coastal Wetland Monitoring Program (Burton et al. 2008, Uzarski et al. 2017) and is used annually by dozens of organizations to survey breeding marsh birds at hundreds of locations throughout the Great Lakes-St. Lawrence region and elsewhere.

The ramifications of using 10 -min versus 15 -min point counts may at first seem trivial, but if timing of call broadcasts within point counts has little or no effect, and if the final $5 \mathrm{~min}$ of 15 min counts adds few new detections given the effort required, then 10-min counts may be more effective. The shortened duration would save 5 min of time during each count and would yield substantial savings if scaled, for example, over the $\sim 2500$ point counts typically conducted annually by organizations across the Great Lakes-St. Lawrence region and beyond (Burton et al. 2008, 
Fig. 1. Locations of 3701 sample points used to assess the influence of call broadcast timing within point counts and survey duration on detection probability of marsh breeding birds throughout the Great Lakes-St. Lawrence region, 2008-2016. Note that for clarity, in most cases, each point represents more than one sample point.

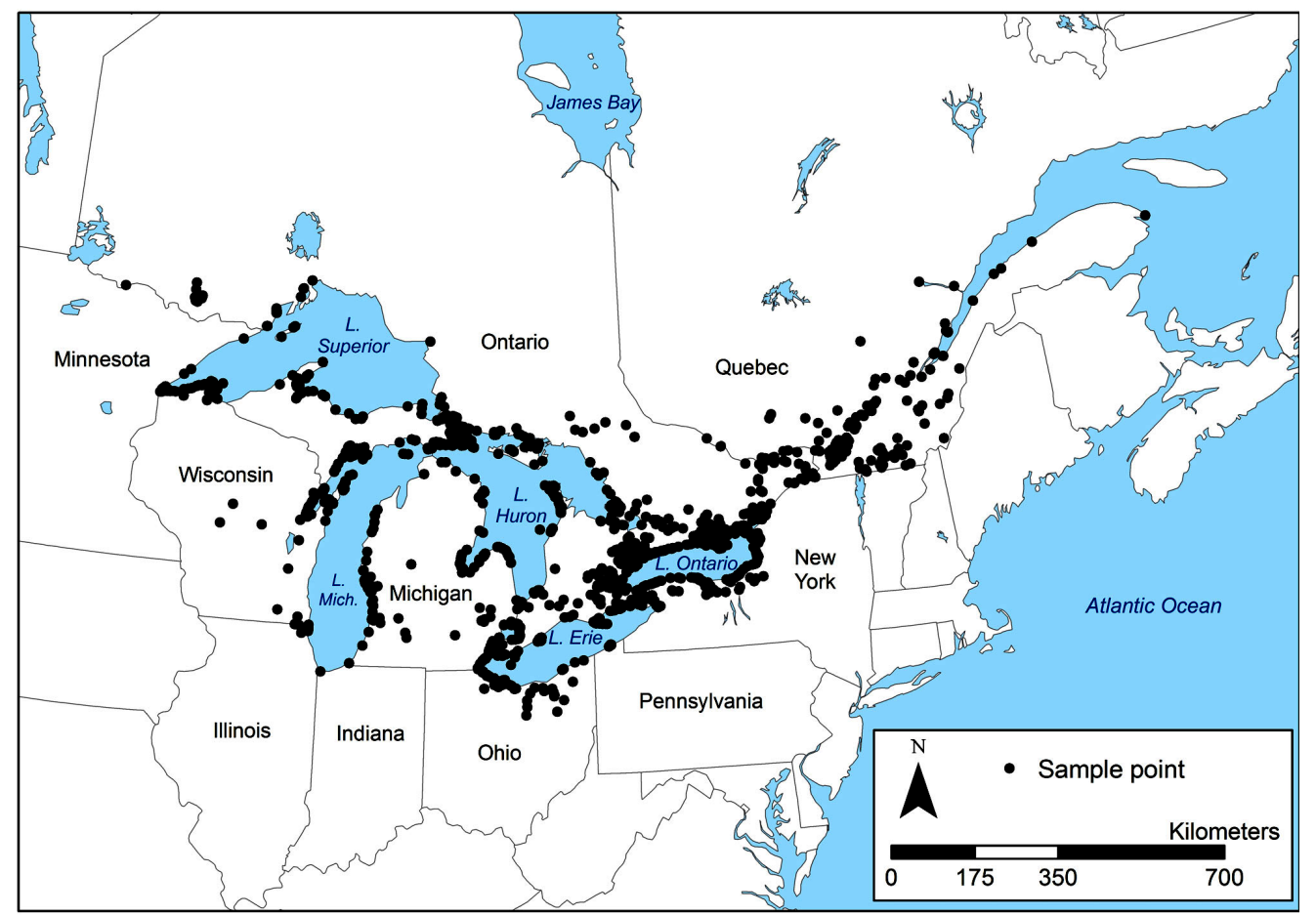

Tozer 2013, 2016, Uzarski et al. 2017). A 5-min reduction in duration for 2500 counts would save 12,500 min or $208 \mathrm{hrs}$ or 26 8-hr work days, which could then yield cost savings or increased sample sizes and associated statistical power if field effort was reallocated to new sample points (Hanowski et al. 2007). Understanding differences in detection during 10-min versus 15min counts is also relevant for justifying the standardized marsh bird protocol (Conway 2011).

Our goal was to assess the influence of the timing of call broadcasts within point counts and point count duration on detection probability of marsh breeding birds observed during point count surveys. For 14 marsh breeding bird species, we compared detection probabilities of individuals during various 5-min periods and combinations of consecutive 5-min periods within 15-min broadcast-assisted point counts. We were particularly interested in potential differences from 10 -min periods depending on whether broadcasts were at the beginning or the end of the $10 \mathrm{~min}$. In addition, we explored differences from the first 5-min passive listening period compared to the second 5-min passive listening period. Finally, we were interested in differences between 10-min and 15-min counts. We used data from 23,973 point counts gathered from two large broad-scale regional marsh breeding bird monitoring programs operating in the Great Lakes-St. Lawrence region. We end with recommendations for surveying marsh breeding birds with point counts.

\section{METHODS}

\section{Study design}

We used data from two large broad-scale marsh breeding bird monitoring programs: Bird Studies Canada's Marsh Monitoring Program (hereafter, MMP) and the multi-institution Great Lakes Coastal Wetland Monitoring Program (hereafter, CWMP) led by Central Michigan University (Fig. 1). The MMP started in the Great Lakes and Québec in 1995 and 2004, respectively, and has operated every year since inception at coastal and inland wetlands throughout much of the Great Lakes-St. Lawrence region (Tozer 2013, 2016). The CWMP started in 2011 and is scheduled to operate until at least 2020 throughout the U.S. and Canadian Great Lakes coastal zones (Uzarski et al. 2017). These programs have somewhat different study designs, but since 2008 they have used identical point count protocols in the field. To garner large numbers of trained participants and achieve large sample sizes at relatively low cost, the MMP allows participants to select survey locations, a justifiable approach if one assumes that the locations are approximately representative of wetlands across a region of interest. By contrast, the CWMP selects survey locations via stratified random sampling of wetlands and conducts bird surveys via paid professional staff. Both monitoring programs target wetlands dominated by nonwoody emergent plants, such as cattails (e.g., Typha sp.) and sedges (e.g., Carex sp.), with surveys located within wetlands. In this paper, we used data from all point 
Fig. 2. Schematic depiction (boxes) of various 5-min periods and combinations of consecutive 5-min periods within broadcast-assisted 15-min point counts used to assess the influence of call broadcast timing within point counts and survey duration on detection probability of marsh birds throughout the Great Lakes-St. Lawrence region, 2008-2016. $\mathrm{P}_{1}=$ first 5-min passive observation period consisting of $\min 1-5, \mathrm{~B}=5$-min broadcast period consisting of min 6-10, $\mathrm{P}_{2}=$ second 5-min passive observation period consisting of $\min 11-15, \mathrm{P}_{1} \mathrm{~B}=$ first 10 min consisting of min $1-10, \mathrm{BP}_{2}=$ second 10 min consisting of $\min 6-15, \mathrm{P}_{1} \mathrm{BP}_{2}=$ entire $15-\mathrm{min}$ point count consisting of min 1-15. Note that the Standardized North American Marsh Bird Monitoring Protocol recommends $\mathrm{P}_{1} \mathrm{~B}$.

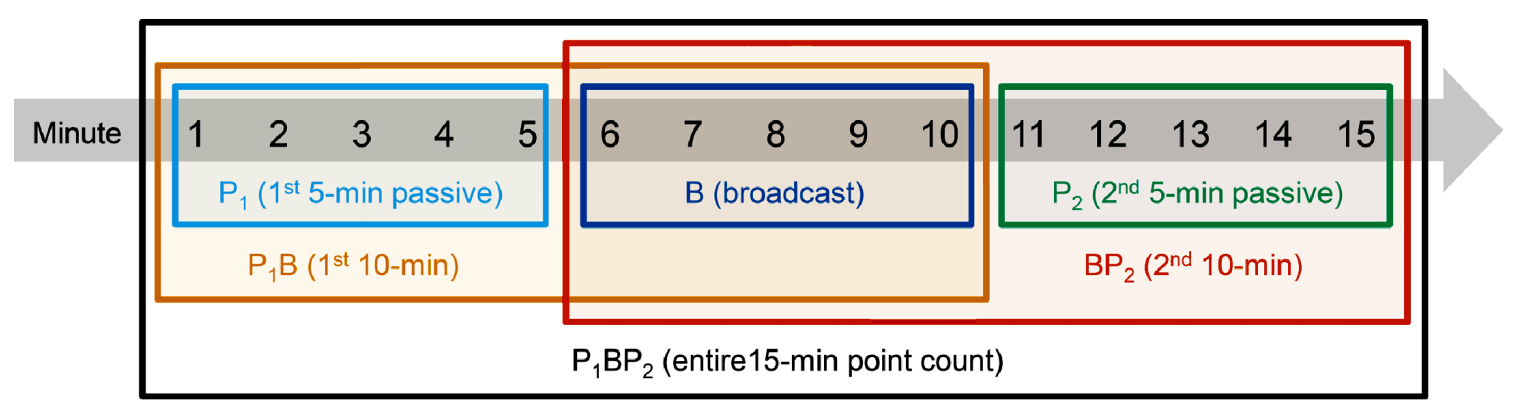

counts conducted by the MMP and the CWMP between 2008 and 2016 in the Great Lakes-St. Lawrence region.

\section{Bird surveys}

Breeding birds were sampled within 100-m-radius semicircular plots from a point at the edge or within a wetland (hereafter, sample point). In most large wetlands sample points were located near the upland / wetland interface (shoreline) or in the interior of the wetland, while in most small wetlands only shoreline points were sampled. Each sample point was surveyed for $15 \mathrm{~min}$ on two visits separated by at least $10-15$ days during the main avian breeding season, typically between late May and early July. Surveys occurred in either the morning $(0.5 \mathrm{hr}$ before local sunrise to $4 \mathrm{hr}$ after local sunrise) or evening ( $4 \mathrm{hr}$ before local sunset to $0.5 \mathrm{hr}$ after local sunset) or both during favorable weather conditions (little to no precipitation; wind: Beaufort 0-3, 0-19 $\mathrm{km} / \mathrm{hr}$ ). Each 15-min survey began with $5 \mathrm{~min}$ of passive (silent) observation, and then 5 min of observation during which elusive species' calls were broadcast, followed by a final 5-min passive observation period. The 1-min broadcast periods consisted of 30 $\mathrm{s}$ of vocalizations followed by $30 \mathrm{~s}$ of silence for each of six species (hereafter, broadcast species) in the following order: Least Bittern (Ixobrychus exilis), Sora (Porzana carolina), Virginia Rail (Rallus limicola), a mixture of American Coot (Fulica americana) and Common Gallinule (Gallinula galeata), and Pied-billed Grebe (Podilymbus podiceps). For each of the broadcast species plus American Bittern (Botaurus lentiginosus), observers recorded the number of individuals detected during each of the three consecutive 5-min periods. Call broadcasts were not used during surveys for American Bittern because the species calls, unsolicited, relatively frequently, early in the breeding season, yet data were collected for it during each 5-min period to provide flexibility during modeling due to its otherwise elusive nature (Lowther et al. 2009). By contrast, for all of the other seven species, observers recorded only the number of new individuals detected during each of the three 5-min periods, which consisted of: Black Tern (Chlidonias niger), Common Grackle (Quiscalus quiscula), Common Yellowthroat (Geothlypis trichas), Marsh
Wren (Cistothorus palustris), Mute Swan (Cygnus olor), Redwinged Blackbird (Agelaius phoeniceus), and Swamp Sparrow (Melospiza georgiana). Observers also recorded a Beaufort wind scale value and temperature during each survey. Further details of the bird survey protocols are described in Bird Studies Canada (2009a,b) and Grabas et al. (2008).

\section{Analysis}

For 14 marsh breeding bird species, we compared detection probabilities of individuals during various 5-min periods and combinations of consecutive 5-min periods within 15-min broadcast-assisted point counts. The various periods or combinations of consecutive periods consisted of the following six segments from each 15-min survey: first 5-min passive observation period consisting of min $1-5$ (hereafter, $\mathrm{P}_{1}$ ), 5-min broadcast period consisting of $\min 6-10$ (hereafter, B), second 5min passive observation period consisting of min 11-15 (hereafter, $\mathrm{P}_{2}$ ), first 10 min consisting of $\mathrm{P}_{1}$ and $\mathrm{B}$ (hereafter, $\mathrm{P}_{1} \mathrm{~B}$ ), second 10 min consisting of $\mathrm{B}$ and $\mathrm{P}_{2}$ (hereafter, $\mathrm{BP}_{2}$ ), and the entire 15-min point count (hereafter, $\mathrm{P}_{1} \mathrm{BP}_{2}$; Fig. 2).

Given that we were interested in differences in detection probabilities of individuals among various periods within point counts, we chose two-level hierarchical $\mathrm{N}$-mixture models for count data, which included an abundance and detection process (Royle 2004a,b). Typically these models are used to describe abundance at the site level and detection at the point count level, with response data consisting of an $\mathrm{R} \times \mathrm{J}$ matrix of count data, where $\mathrm{R}$ is the number of sites and $\mathrm{J}$ is the maximum number of observations or sampling periods per site, but the models are not exclusively restricted to this type of data structure (Fiske and Chandler 2017, Fiske et al. 2017). For our purposes, R was the number of point counts and $\mathrm{J}$ was the maximum number of observations or sampling periods per point count. This approach described abundance at the point count level and detection at the level of 5-min periods within point counts, which produced results in keeping with our primary goal. 
We parameterized models using the unmarked package (Fiske et al. 2017) in Program R ( $\mathrm{R}$ version 2.14.2; $\mathrm{R}$ Core Team 2012). For broadcast species and American Bittern, the counts were the number of individuals detected during each of the three consecutive 5-min periods, which we modeled using $N$-mixture models for repeated count data via the pcount function in unmarked. In these models, the detection process described the probability of detecting an individual marsh breeding bird within a 5-min period (Royle 2004b). For all other species, the counts were the number of new individuals detected during each of the three 5-min periods, which were modeled using multinomial $N$ mixture models for data collected using removal sampling via the multinomPois function in unmarked. In these models, the detection process described the probability of detecting a new individual marsh breeding bird within a 5-min period (Royle 2004a).

For each species, we fit a single model for inference that included multiple covariates known to influence detection probability in marsh breeding birds (Fig. 3; reviewed in Conway and Gibbs 2011). We chose this approach over multiple competing models for each species to keep the number of models and associated runtime manageable, which we justified given that detection in most of the species we analyzed has been shown to be influenced by most of the covariates we considered (Tozer 2016, Tozer et al. 2016). In the detection process, we modeled the effect of consecutive 5-min periods (hereafter a categorical variable named "period" with three levels: $\mathrm{P}_{1}, \mathrm{~B}$, or $\mathrm{P}_{2}$ ), different marsh bird monitoring programs (hereafter a categorical variable named "program" with two levels: CWMP or MMP), day of the year (hereafter a continuous variable named "date"; e.g., $1=$ Jan 1), hours to or since sunrise or sunset (hereafter a continuous variable named "daylight" such that negative numbers were during dark and positive values were during light), morning or evening (hereafter a categorical variable named "time of day" with two levels: morning or evening), wind speed (hereafter a continuous variable named "wind" consisting of Beaufort wind scale values), and air temperature (hereafter a continuous variable named "temperature" measured in degrees Celsius). In the abundance process, we modeled the effect of year (hereafter a continuous variable named "year") to account for abundance of most of the species increasing or decreasing over the duration of the study (Tozer 2013, 2016), and to account for residual spatial autocorrelation in model predictions, we included the effect of latitude, longitude, latitude ${ }^{2}$, longitude ${ }^{2}$, and latitude $\times$ longitude (Schuster and Arcese 2013, Tozer 2016).

For broadcast species, we fit three separate models with a Poisson, zero-inflated Poisson, or negative binomial distribution, and performed further modeling with the distribution that had the lowest Akaike's Information Criterion (AIC) value. For all other species, a Poisson distribution was used because this was the only distribution available in the multinomPois function in unmarked. All continuous covariates were z-transformed prior to analysis. We tested the overall fit of the model for each species using a parametric bootstrap procedure and the Freeman-Tukey fit statistic (Fiske and Chandler 2017).

To obtain estimates and associated error of abundance, we made predictions on the log scale and back-transformed to the response scale using the log link function, and to obtain estimates and
Fig. 3. Number of point counts (surveys) as a function of covariates used to assess the influence of call broadcast timing within point counts and survey duration on detection probability of marsh breeding birds throughout the Great Lakes-St. Lawrence region, 2008-2016.
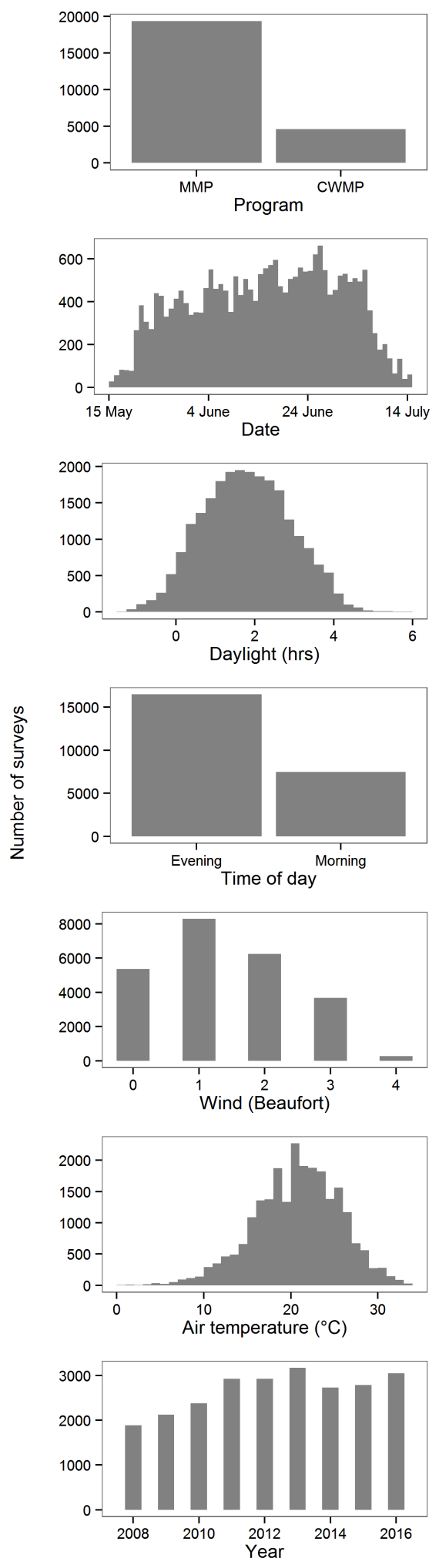
associated error of detection probability for $\mathrm{P}_{1}, \mathrm{~B}$, and $\mathrm{P}_{2}$, we made predictions on the logit scale and back-transformed to the response scale using the logit link function. We obtained estimates of detection probabilities for $\mathrm{P}_{1} \mathrm{~B}, \mathrm{BP}_{2}$, and $\mathrm{P}_{1} \mathrm{BP}_{2}$ using parametric bootstrapping with 100 iterations and the following equations: $\mathrm{P}_{1} \mathrm{~B}=1-\left(1-\mathrm{P}_{1}\right) *(1-\mathrm{B}), \mathrm{BP}_{2}=1-(1-\mathrm{B}) *\left(1-\mathrm{P}_{2}\right)$, $\mathrm{P}_{1} \mathrm{BP}_{2}=1-\left(1-\mathrm{P}_{1}\right) *(1-\mathrm{B}) *\left(1-\mathrm{P}_{2}\right)$. We accomplished the latter by writing an $\mathrm{R}$-function that calculated the above equations, and then we fed the R-function into the parboot function in unmarked. We were able to generate estimates of detection for broadcast species and American Bittern during all six segments within point counts $\left(\mathrm{P}_{1}, \mathrm{~B}, \mathrm{P}_{2}, \mathrm{P}_{1} \mathrm{~B}, \mathrm{BP}_{2}\right.$, and $\left.\mathrm{P}_{1} \mathrm{BP}_{2}\right)$. By contrast, we were only able to generate estimates for all of the other species during five segments $\left(\mathrm{P}_{1}, \mathrm{~B}, \mathrm{P}_{2}, \mathrm{P}_{1} \mathrm{~B}\right.$, and $\left.\mathrm{P}_{1} \mathrm{BP}_{2}\right)$ because $\mathrm{BP}_{2}$ was not estimable using removal sampling. To explore differences between various periods within point counts for each species, we plotted model-predicted detection probabilities and associated $95 \%$ confidence intervals for various 5-min periods and combinations of consecutive 5-min periods (e.g., $\mathrm{P}_{1} \mathrm{~B}$ ). We also calculated the mean and range of detection probabilities during various periods for some groups of species. We concluded that detection probabilities were significantly different when $95 \%$ confidence intervals did not overlap.

We restricted our analysis to 14 marsh breeding bird species targeted by marsh bird monitoring programs in the Great LakesSt. Lawrence region (e.g., Tozer 2013, 2016). We did not account for differences in observers because the large broad-scale monitoring data that we worked with had hundreds of different observers, and by extension hundreds of corresponding parameters to estimate, which made modeling impractical, if not impossible.

\section{RESULTS}

We analyzed 23,973 point counts conducted between 2008 and 2016 at 3701 sample points throughout the Great Lakes-St. Lawrence region (Fig. 1). Mean number of individuals detected per point count varied among species from as low as 0.03 to as high as 4.6 (Figs. 4, 5). Red-winged Blackbird, Swamp Sparrow, Marsh Wren, and Common Yellowthroat were most abundant, whereas American Coot, Least Bittern, Common Gallinule, and Mute Swan were least abundant (Figs. 4, 5). Detection probability during $\mathrm{P}_{1}$, which was the most comparable across all of the species, varied in increasing order as follows: Virginia Rail (0.08), Sora (0.12), Common Gallinule (0.13), American Coot (0.14), Black Tern (0.20), Common Grackle (0.20), Pied-billed Grebe (0.25), Least Bittern (0.28), Common Yellowthroat (0.33), Marsh Wren (0.38), Swamp Sparrow (0.47), American Bittern (0.55), Redwinged Blackbird (0.56), and Mute Swan (0.58; Figs. 4, 5).

Models for each of the broadcast species and American Bittern fit adequately (all $\mathrm{P}>0.05$ ), and generated realistic abundance and detection estimates (Fig. 4). For the majority of these species, the negative binomial distribution provided the best-fitting binomial $N$-mixture model, but for Common Gallinule, Least Bittern, and Pied-billed Grebe a zero-inflated Poisson distribution had better fit. By contrast, according to Freeman-Tukey fit statistics, multinomial $N$-mixture models fit poorly for all other species. By default, these models used a Poisson distribution. Nonetheless, we used the multinomial $\mathrm{N}$-mixture models for inference because they yielded realistic estimates of abundance and detection (Fig. 5).
We included a number of covariates in our models (Fig. 3), most of which influenced abundance and detection in different ways, depending on the species (Table 1,2). With the exception of each of the three consecutive 5-min periods within point counts, there was no consistent pattern in the influence of any particular covariate on abundance or detection across species (Table 1, 2). For instance, there was a significant influence of year on abundance and a significant influence of program, date, daylight, time of day, wind, and temperature on detection in $64-79 \%$ of species depending on the covariate, yet in each case there was a mix of significant positive and negative estimates (Table 1, 2). It is worth noting that abundance in $50 \%$ of species significantly decreased over the years of the study (Table 1,2). In addition, detection in $50-64 \%$ of species was significantly higher for the MMP compared to the CWMP, significantly decreased as the season progressed, significantly decreased as the number of hours to sunset or since sunrise increased, or was significantly higher during morning compared to evening (Table 1,2).

For each broadcast species and American Bittern, there was no significant difference in detection probability during $\mathrm{P}_{1} \mathrm{~B}$ compared to $\mathrm{BP}_{2}$ (Fig. 4), indicating that the timing of call broadcasts within 10-min point counts had no influence on detection. By contrast, detection probability was significantly higher during $\mathrm{P}_{1}$ compared to $\mathrm{P}_{2}$ in American Bittern, significantly lower during $P_{1}$ compared to $P_{2}$ in Least Bittern and Virginia Rail, and not significantly different during $P_{1}$ compared to $\mathrm{P}_{2}$ in American Coot, Common Gallinule, Pied-billed Grebe, and Sora (Fig. 4), showing that the timing of 5-min passive listening periods relative to broadcasts within point counts influenced detection in some species. As expected, detection probability was significantly higher for all of the broadcast species during B compared to passive observation periods, especially for Common Gallinule, Sora, and Virginia Rail, for which detection probability was about $40 \%$ during B and approximately $<20 \%$ during passive observation periods (Fig. 4). Detection probability was not significantly different during $\mathrm{P}_{1} \mathrm{~B}$ compared to $\mathrm{P}_{1} \mathrm{BP}_{2}$ in American Coot, Common Gallinule, and Sora, whereas detection was significantly higher during $\mathrm{P}_{1} \mathrm{BP}_{2}$ compared to $\mathrm{P}_{1} \mathrm{~B}$ in American Bittern, Least Bittern, Pied-billed Grebe, and Virginia Rail, although the difference in detection between the two periods for these four species was surprisingly small relative to the difference in observation time: $\mathrm{P}_{1} \mathrm{~B}: 0.60(0.50-0.76)$ (mean [range]); $\mathrm{P}_{1} \mathrm{BP}_{2}: 0.71$ (0.59-0.87; Fig. 4).

In each of the remaining species, except Common Grackle, detection probability of new individuals was significantly lower during $\mathrm{B}$ compared to $\mathrm{P}_{1}$ (Fig. 5). By contrast, in each of the remaining species, detection of new individuals was not significantly different during $\mathrm{P}_{2}$ compared to $\mathrm{B}$ (Fig. 5). Detection probability of new individuals was also not significantly different during $\mathrm{P}_{1} \mathrm{~B}$ compared to $\mathrm{P}_{1} \mathrm{BP}_{2}$ in Black Tern, Common Grackle, Marsh Wren, and Mute Swan, whereas detection of new individuals was significantly higher during $\mathrm{P}_{1} \mathrm{BP}_{2}$ compared to $\mathrm{P}_{1} \mathrm{~B}$ in Common Yellowthroat, Red-winged Blackbird, and Swamp Sparrow, although the difference in detection of new individuals between the two periods for these three species was surprisingly small relative to the difference in observation time: $\mathrm{P}_{1} \mathrm{~B}: 0.58$ (0.44-0.68) (mean [range]); $\mathrm{P}_{1} \mathrm{BP}_{2}: 0.67$ (0.53-0.77) (Fig. $5)$. 
Fig. 4. Detection probability of individuals of some marsh breeding bird species ( $\pm 95 \%$ confidence intervals) during various 5 -min periods and combinations of consecutive 5-min periods during 23,973 broadcast-assisted 15-min point counts throughout the Great Lakes-St. Lawrence region, 2008-2016. $\mathrm{P}_{1}=$ first 5-min passive observation period consisting of min 1-5, B = 5-min broadcast period consisting of min 6-10, $\mathrm{P}_{2}=$ second 5-min passive observation period consisting of min $11-15$, $\mathrm{P}_{1} \mathrm{~B}=$ first 10 min consisting of $\min 1-10, \mathrm{BP}_{2}=$ second $10 \mathrm{~min}$ consisting of $\min 6-15, \mathrm{P}_{1} \mathrm{BP}_{2}=$ entire 15 -min point count consisting of min $1-15$. See Fig. 2 for a schematic depiction of the periods and combinations of consecutive periods. Predicted abundance (lower, upper $95 \%$ confidence interval) from binomial $N$-mixture models also shown at the top of each panel for each species.
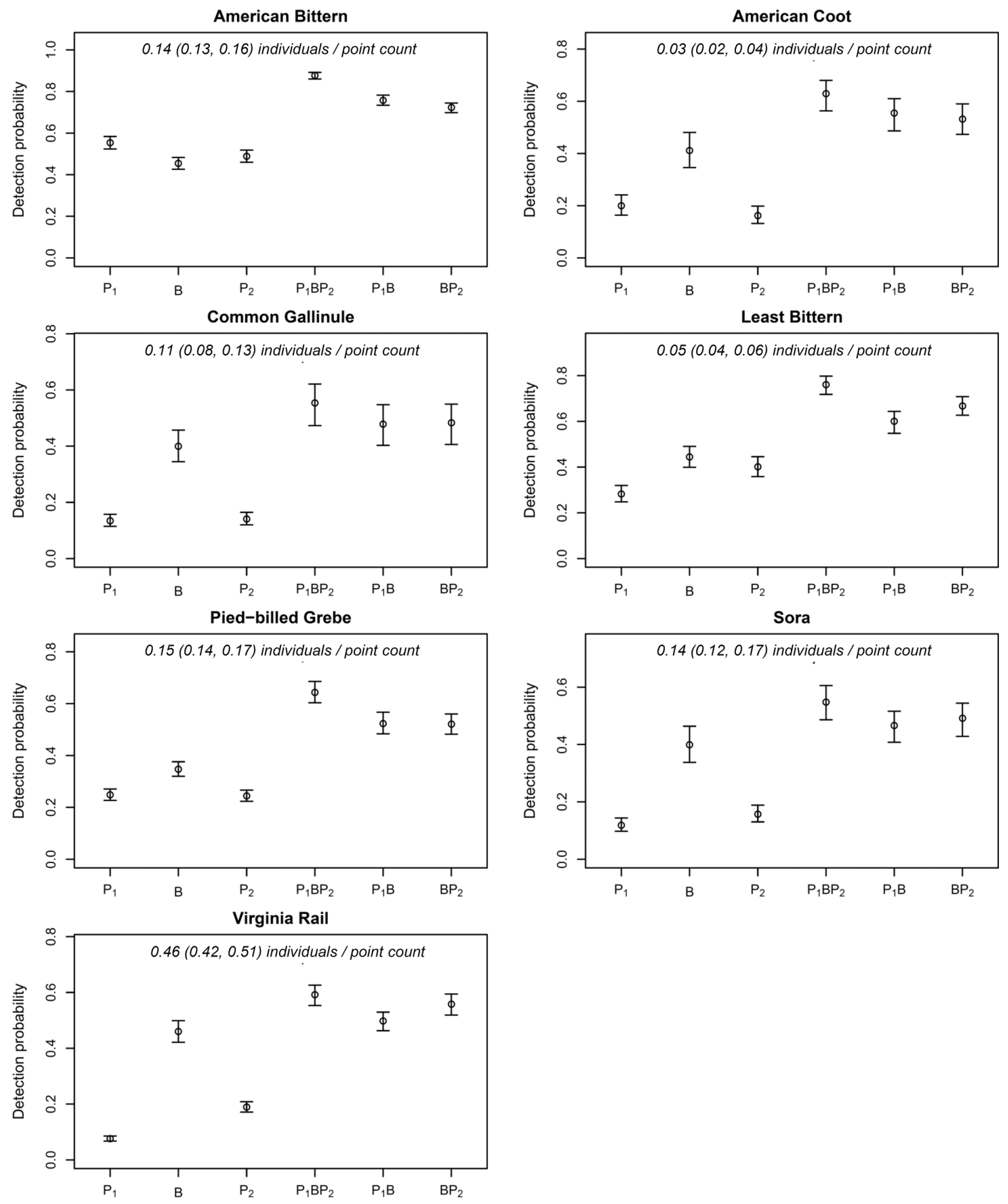
Fig. 5. Detection probability of new individuals of some marsh breeding bird species ( $\pm 95 \%$ confidence intervals) during various 5 min periods and combinations of consecutive 5-min periods during 23,973 broadcast-assisted 15-min point counts throughout the Great Lakes-St. Lawrence region, 2008-2016. $\mathrm{P}_{1}=$ first 5-min passive observation period consisting of min $1-5$, B $=5$-min broadcast period consisting of $\min 6-10, \mathrm{P}_{2}=$ second 5-min passive observation period consisting of min $11-15, \mathrm{P}_{1} \mathrm{~B}=$ first 10 min consisting of $\min 1-10, \mathrm{P}_{1} \mathrm{BP}_{2}=$ entire 15-min point count consisting of min 1-15. See Fig. 2 for a schematic depiction of the periods and combinations of consecutive periods. Predicted abundance (lower, upper $95 \%$ confidence interval) from multinomial $N$ mixture models also shown at the top of each panel for each species.
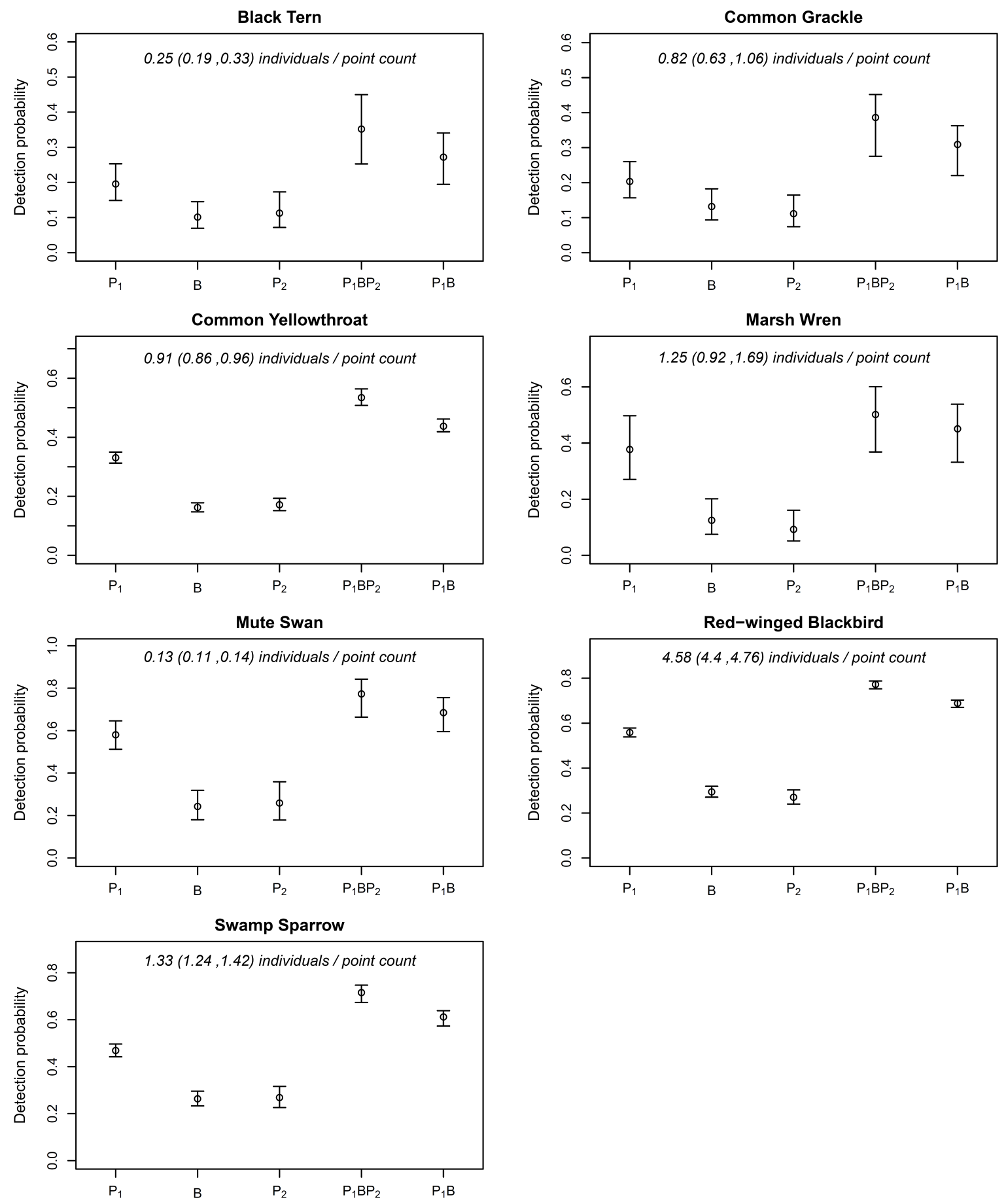
Table 1. Parameter estimates from binomial $N$-mixture models used to assess the influence of call broadcast timing within point counts and survey duration on detection probability of marsh breeding birds throughout the Great Lakes-St. Lawrence region, $2008-2016$. Standard error is given below each estimate in parentheses, with an asterisk indicating statistical significance at $\mathrm{P}<0.05$. $\mathrm{P}_{1}=$ first 5 min passive observation period consisting of $\min 1-5, \mathrm{~B}=5$-min broadcast period consisting of $\min 6-10, \mathrm{P}_{2}=$ second 5-min passive observation period consisting of min 11-15, CWMP $=$ Coastal Wetland Monitoring Program, AMBI $=$ American Bittern $($ Botaurus lentiginosus), $\mathrm{AMCO}=$ American Coot (Fulica americana), COGA = Common Gallinule $($ Gallinula galeata $), \mathrm{LEBI}=\mathrm{Least}$ Bittern (Ixobrychus exilis), PBGR = Pied-billed Grebe $($ Podilymbus podiceps $)$, SORA = Sora (Porzana carolina $),$ VIRA = Virginia Rail $($ Rallus limicola).

\begin{tabular}{|c|c|c|c|c|c|c|c|}
\hline \multirow[b]{2}{*}{ Parameter } & \multicolumn{7}{|c|}{ Species } \\
\hline & AMBI & $\mathrm{AMCO}$ & COGA & LEBI & PBGR & SORA & VIRA \\
\hline \multicolumn{8}{|l|}{ Abundance } \\
\hline Intercept & $-0.72(0.06)^{*}$ & $-3.45(0.16)^{*}$ & $0.43(0.09)^{*}$ & $-2.97(0.06)^{*}$ & $-0.29(0.06)^{*}$ & $-1.95(0.09)^{*}$ & $-0.78(0.05)^{*}$ \\
\hline Year & $-0.01(0.02)$ & $-0.07(0.06)$ & $-0.04(0.03)$ & $0.04(0.04)$ & $-0.15(0.02)^{*}$ & $0.06(0.04)$ & $-0.05(0.02)^{*}$ \\
\hline Latitude & $0.44(0.04)^{*}$ & $-0.46(0.11)^{*}$ & $-0.68(0.07)^{*}$ & $-0.62(0.08)^{*}$ & $-0.01(0.04)$ & $0.93(0.06)^{*}$ & $0.71(0.04)^{*}$ \\
\hline Latitude $^{2}$ & $-0.12(0.03)^{*}$ & $0.21(0.05)^{*}$ & $-0.11(0.05)^{*}$ & $-0.15(0.05)^{*}$ & $0.07(0.02)^{*}$ & $-0.18(0.03)^{*}$ & $-0.28(0.02)^{*}$ \\
\hline Longitude & $0.4(0.05)^{*}$ & $-0.41(0.1)^{*}$ & $0.67(0.06)^{*}$ & $0.23(0.06)^{*}$ & $-0.11(0.04)^{*}$ & $-0.8(0.06)^{*}$ & $-0.11(0.04)^{*}$ \\
\hline Longitude $^{2}$ & $-0.12(0.03)^{*}$ & $0.22(0.07)^{*}$ & $-0.14(0.06)^{*}$ & $0.05(0.05)$ & $0.02(0.02)$ & $-0.11(0.03)^{*}$ & $-0.14(0.02)^{*}$ \\
\hline Latitude x Longitude & $-0.11(0.03)^{*}$ & $0.43(0.06)^{*}$ & $0.38(0.05)^{*}$ & $0.06(0.06)$ & $0.32(0.03)^{*}$ & $0.42(0.04)^{*}$ & $0.16(0.03)^{*}$ \\
\hline \multicolumn{8}{|l|}{ Detection } \\
\hline $\mathrm{P}_{1}$ & $0.24(0.06)^{*}$ & $-1.82(0.17)^{*}$ & $-1.86(0.09)^{*}$ & $-0.93(0.09)^{*}$ & $-1.11(0.06)^{*}$ & $-2.01(0.11)^{*}$ & $-2.5(0.07)^{*}$ \\
\hline $\mathrm{B}^{1}$ & $-0.16(0.06)^{*}$ & $-0.9(0.2)^{*}$ & $-0.41(0.12)^{*}$ & $-0.22(0.09)^{*}$ & $-0.63(0.06)^{*}$ & $-0.41(0.13)^{*}$ & $-0.16(0.08) *$ \\
\hline $\mathrm{P}_{2}$ & $-0.02(0.06)$ & $-2.06(0.17)^{*}$ & $-1.81(0.09)^{*}$ & $-0.4(0.09)^{*}$ & $-1.13(0.06)^{*}$ & $-1.68(0.11)^{*}$ & $-1.46(0.06)^{*}$ \\
\hline Program (CWMP) & $-0.67(0.16)^{*}$ & $-1.8(0.26)^{*}$ & $0.14(0.14)$ & $-0.05(0.17)$ & $-0.64(0.12)^{*}$ & $-1.51(0.14)^{*}$ & $-1.23(0.09)^{*}$ \\
\hline Day of the year & $-0.52(0.04)^{*}$ & $-0.33(0.08)^{*}$ & $-0.08(0.04)$ & $-0.35(0.06)^{*}$ & $-0.11(0.03)^{*}$ & $-0.22(0.05)^{*}$ & $-0.05(0.03)$ \\
\hline Daylight & $-0.36(0.04)^{*}$ & $-0.17(0.08)^{*}$ & $-0.04(0.05)$ & $-0.35(0.06)^{*}$ & $0.02(0.03)$ & $0.03(0.05)$ & $-0.01(0.03)$ \\
\hline Time of day (morning) & $-1.01(0.1)^{*}$ & $0.06(0.21)$ & $0.33(0.11)^{*}$ & $0.23(0.12)$ & $0.93(0.08)^{*}$ & $-0.47(0.12)^{*}$ & $-0.21(0.07)^{*}$ \\
\hline Wind & $-0.07(0.03)^{*}$ & $-0.13(0.08)$ & $-0.04(0.04)$ & $0.02(0.06)$ & $0.03(0.03)$ & $-0.13(0.04)^{*}$ & $-0.12(0.03)^{*}$ \\
\hline Temperature & $-0.26(0.04)^{*}$ & $-0.11(0.09)$ & $0.01(0.05)$ & $0.13(0.07)^{*}$ & $0.15(0.04)^{*}$ & $-0.23(0.06)^{*}$ & $-0.05(0.04)$ \\
\hline Dispersion & $0.88(0.07)^{*}$ & $-3.07(0.1)^{*}$ & $2.53(0.04)^{*}$ & $-1.57(0.13)^{*}$ & $1.39(0.04)^{*}$ & $-2.08(0.09)^{*}$ & $-1.2(0.05)^{*}$ \\
\hline
\end{tabular}

\section{DISCUSSION}

Timing of call broadcasts within point counts had no influence on detection probabilities of broadcast species during 10-min point count surveys in this study. For each broadcast species and American Bittern, there was no significant difference in detection probability during $\mathrm{P}_{1} \mathrm{~B}$ compared to $\mathrm{BP}_{2}$. This suggests that steps to keep the timing of broadcasts consistent within marsh breeding bird point counts across years and programs are not needed when analyzing data from entire 10-min surveys.

Point count results from marsh breeding bird monitoring programs are typically used in at least two different types of calculations. One is estimating change in species over time, such as the percent change in occupancy or abundance per year, and the other is estimating occupancy or population size of species in a certain area at a particular time (MacKenzie et al. 2003, Royle $2004 a, b$ ). For estimating or modeling change, occurrence or counts of individuals from call broadcast-assisted point counts are often used as the response variable (e.g., Tozer 2016, Correll et al. 2017). This is because broadcasts dramatically increase detections of elusive species, and increased detections result in increased statistical power to detect trends (Steidl et al. 2013). We found no significant difference in detection probabilities of broadcast species and American Bittern in relation to the timing of broadcasts within 10-min point counts. Therefore, the timing of broadcasts within 10-min counts should not cause bias when modeling population change for American Coot, Common
Gallinule, Least Bittern, Pied-billed Grebe, Sora, Virginia Rail, or American Bittern based on counts from entire 10-minute surveys. Based on our study, valid analysis of population trends for these species across years should be possible based on data where the timing of broadcasts within 10-min point counts differs among years in the time series.

When estimating occupancy or population size within a certain area, occurrences or counts from only the passive period rather than all of the periods within point counts are typically used as the response variable (e.g., Wiest et al. 2016). This is because individuals may be drawn closer to the observer by broadcasts before they become available for detection, which might make occupancy and density estimates biased because the effective survey area is uncertain (Conway 2011). We found that detection probability in nearly two-thirds of broadcast species and American Bittern was not significantly different during $P_{1}$ compared to $\mathrm{P}_{2}$, whereas detection probability was significantly different during these two periods in three species. In Least Bittern and Virginia Rail, detection probability was significantly higher during $\mathrm{P}_{2}$ compared to $\mathrm{P}_{1}$, perhaps because of elevated activity levels caused by broadcasts. By contrast, in American Bittern, detection probability was significantly higher during $\mathrm{P}_{1}$ compared to $\mathrm{P}_{2}$, the reasons for which are unclear. This species was analyzed in the same manner as broadcast species because similar data were available, but broadcasts of its calls were not used during surveys, so the difference was not related to conspecific broadcasts. A possible explanation is that observers were more likely to record 
Table 2. Parameter estimates from multinomial $N$-mixture models used to assess the influence of call broadcast timing within point counts and survey duration on detection probability of marsh breeding birds throughout the Great Lakes-St. Lawrence region, 20082016. Standard error is given below each estimate in parentheses, with an asterisk indicating statistical significance at $\mathrm{P}<0.05$. $\mathrm{P}_{1}=$ first 5-min passive observation period consisting of $\min 1-5, \mathrm{~B}=5$-min broadcast period consisting of min $6-10$, $\mathrm{P}_{2}=$ second 5-min passive observation period consisting of $\min 11-15, \mathrm{CWMP}=$ Coastal Wetland Monitoring Program, BLTE $=$ Black Tern $($ Chlidonias niger), $\mathrm{COGR}=$ Common Grackle (Quiscalus quiscula), COYE = Common Yellowthroat (Geothlypis trichas), MAWR $=$ Marsh Wren (Cistothorus palustris), MUSW = Mute Swan(Cygnus olor), RWBL = Red-winged Blackbird (Agelaius phoeniceus), SWSP $=$ Swamp Sparrow (Melospiza georgiana).

\begin{tabular}{|c|c|c|c|c|c|c|c|}
\hline \multirow[b]{2}{*}{ Parameter } & \multicolumn{7}{|c|}{ Species } \\
\hline & BLTE & COGR & COYE & MAWR & MUSW & RWBL & SWSP \\
\hline \multicolumn{8}{|l|}{ Abundance } \\
\hline Intercept & $-1.38(0.14)^{*}$ & $-0.2(0.13)$ & $-0.09(0.03)^{*}$ & $0.22(0.16)$ & $-2.06(0.06)^{*}$ & $1.52(0.02)^{*}$ & $0.29(0.03)^{*}$ \\
\hline Year & $-0.2(0.02)^{*}$ & $0.02(0.01)^{*}$ & $-0.03(0.01)^{*}$ & $-0.02(0.01)^{*}$ & $0.18(0.03)^{*}$ & $-0.02(0)^{*}$ & $-0.02(0.01)^{*}$ \\
\hline Latitude & $0.8(0.04)^{*}$ & $-0.05(0.02)^{*}$ & $-0.14(0.01)^{*}$ & $-0.61(0.02)^{*}$ & $-0.81(0.11)^{*}$ & $-0.19(0.01)^{*}$ & $0.07(0.01)^{*}$ \\
\hline Latitude $^{2}$ & $-0.16(0.02)^{*}$ & $-0.1(0.01)^{*}$ & $-0.01(0.01)$ & $-0.12(0.01)^{*}$ & $-1.69(0.09)^{*}$ & $-0.04(0)^{*}$ & $-0.18(0.01)^{*}$ \\
\hline Longitude & $-0.6(0.04)^{*}$ & $0.29(0.02)^{*}$ & $-0.11(0.01)^{*}$ & $0.11(0.02)^{*}$ & $-0.55(0.07)^{*}$ & $0.01(0.01)$ & $0.42(0.01)^{*}$ \\
\hline Longitude $^{2}$ & $-0.2(0.03)^{*}$ & $0.11(0.01)^{*}$ & $0(0.01)$ & $0(0.01)$ & $-0.25(0.06)^{*}$ & $0.05(0)^{*}$ & $-0.03(0.01)^{*}$ \\
\hline Latitude x Longitude & $0.45(0.03)^{*}$ & $0.06(0.01)^{*}$ & $-0.02(0.01)^{*}$ & $-0.05(0.01)^{*}$ & $0.72(0.09)^{*}$ & $0.05(0)^{*}$ & $-0.27(0.01)^{*}$ \\
\hline \multicolumn{8}{|l|}{ Detection } \\
\hline $\mathrm{P}_{1}$ & $-1.41(0.17)^{*}$ & $-1.36(0.16)^{*}$ & $-0.7(0.04)^{*}$ & $-0.5(0.25)^{*}$ & $0.32(0.14)^{*}$ & $0.24(0.04)^{*}$ & $-0.12(0.06)^{*}$ \\
\hline $\mathrm{B}^{1}$ & $-2.18(0.21)^{*}$ & $-1.89(0.2)^{*}$ & $-1.64(0.06)^{*}$ & $-1.95(0.29)^{*}$ & $-1.14(0.19)^{*}$ & $-0.87(0.06)^{*}$ & $-1.03(0.08)^{*}$ \\
\hline $\mathrm{P}_{2}$ & $-2.06(0.25)^{*}$ & $-2.07(0.23)^{*}$ & $-1.58(0.07)^{*}$ & $-2.28(0.32)^{*}$ & $-1.05(0.24)^{*}$ & $-0.99(0.08)^{*}$ & $-1(0.12)^{*}$ \\
\hline Program (CWMP) & $-2.92(0.2)^{*}$ & $-0.1(0.05)$ & $0.63(0.06)^{*}$ & $-0.45(0.05)^{*}$ & $2.26(0.32)^{*}$ & $-0.07(0.04)^{*}$ & $0.03(0.07)$ \\
\hline Day of the year & $-0.03(0.04)$ & $-0.16(0.02)^{*}$ & $0.03(0.02)$ & $0.13(0.02)^{*}$ & $-0.32(0.08)^{*}$ & $-0.24(0.01)^{*}$ & $0.34(0.02)^{*}$ \\
\hline Daylight & $0.27(0.05)^{*}$ & $-0.14(0.02)^{*}$ & $-0.11(0.02)^{*}$ & $-0.29(0.04)^{*}$ & $-0.28(0.08)^{*}$ & $-0.15(0.01)^{*}$ & $-0.11(0.02)^{*}$ \\
\hline Time of day (morning) & $0.68(0.13)^{*}$ & $0.49(0.05)^{*}$ & $0.77(0.05)^{*}$ & $0.1(0.04)^{*}$ & $-0.29(0.19)$ & $-0.09(0.02)^{*}$ & $0.16(0.05)^{*}$ \\
\hline Wind & $0.38(0.04)^{*}$ & $0(0.02)$ & $-0.16(0.02)^{*}$ & $0.09(0.02)^{*}$ & $0.27(0.08)^{*}$ & $-0.06(0.01) *$ & $-0.05(0.02)^{*}$ \\
\hline Temperature & $0.09(0.06)$ & $-0.02(0.02)$ & $0.09(0.02)^{*}$ & $0.06(0.02)^{*}$ & $-0.29(0.11)^{*}$ & $0.08(0.01)^{*}$ & $-0.09(0.02)^{*}$ \\
\hline
\end{tabular}

American Bittern at the beginning of the survey, artificially raising detection during the first 5-min, and were less likely to record it after because the American Bittern calls frequently and is very loud and obvious when it calls. To avoid bias when estimating occupancy or population sizes within certain areas or during other analyses that require unbiased estimates, we recommend conducting passive observation periods before broadcasts rather than after broadcasts. We note that even though this recommendation applies to only two broadcast species in our study that showed significant differences between $\mathrm{P}_{1}$ compared to $\mathrm{P}_{2}$, it is justified because the same amount of time is required for $\mathrm{P}_{1} \mathrm{~B}$ and $\mathrm{BP}_{2}$, so nothing is lost in terms of effort or associated statistical power as described above by favoring $\mathrm{P}_{1} \mathrm{~B}$ over $\mathrm{BP}_{2}$, plus $\mathrm{P}_{1} \mathrm{~B}$ comes with the advantage of being consistent with the standardized marsh bird protocol (Conway 2011).

Considering the amount of effort involved with the addition of $\mathrm{P}_{2}$, we found surprisingly small but significant differences in detection probability in 7 of the 14 species during $\mathrm{P}_{1} \mathrm{~B}$ compared to $\mathrm{P}_{1} \mathrm{BP}_{2}$. Detection in a little over half of broadcast species and American Bittern was significantly higher during $\mathrm{P}_{1} \mathrm{BP}_{2}$ compared to $\mathrm{P}_{1} \mathrm{~B}$, and detection of new individuals in nearly half of the remaining species was significantly higher during $\mathrm{P}_{1} \mathrm{BP}_{2}$ compared to $\mathrm{P}_{1} \mathrm{~B}$. However, the magnitude of these significant differences was unexpectedly small relative to the difference in observation time. Increasing point count duration from $10 \mathrm{~min}$ to $15 \mathrm{~min}$ required $50 \%$ more time spent observing at sample points, whereas the corresponding percent increase in mean detection probability for species showing significant differences was $19 \%$ for broadcast species and American Bittern and $16 \%$ for the remaining species. Thus, even though detection probability differed significantly in half of the species during $\mathrm{P}_{1} \mathrm{~B}$ compared to $\mathrm{P}_{1} \mathrm{BP}_{2}$, we suggest, as elaborated below, that the effort spent observing each point for an additional $5 \mathrm{~min}$ is better spent elsewhere.

A major design question of any bird monitoring program is whether surveying more sample points with less effort per point is better than surveying fewer points with more effort per point. The answer depends on the question being addressed and the travel time between points. For monitoring population trends in marsh breeding birds over time, both Hanowski et al. (2007) and Steidl et al. (2013) concluded that maximizing the number of sample points is generally economically and statistically more effective than resampling established points, assuming that the prescribed point counts satisfy at least a minimum threshold of sufficient effort. Hanowski et al. (2007) even recommended no resampling during Great Lakes coastal marsh bird surveys unless all possible wetlands are surveyed at least once. We note that we did not evaluate trade-offs between the number of sample points and the amount of resampling relative to statistical power in this study. However, in keeping with the conclusions of Hanowski et al. (2007) and Steidl et al. (2013), we suggest that the significant gains in detection probability with $15 \mathrm{~min}$ of surveying compared to $10 \mathrm{~min}$ in 7 of the 14 species were small enough that the final 5 min of 15 -min point counts be invested in sampling additional points elsewhere whenever possible. This is especially true when additional points in close proximity to the initial sample points 
can be sampled in wetlands that would otherwise remain unsampled (i.e., when travel time between points is relatively small), without violating statistical assumptions of spatial independence. Given that population trend analysis is an objective of many marsh bird monitoring programs, according to Hanowski et al. (2007) and Steidl et al. (2013), our recommendation of 10-min surveys instead of 15-min surveys could result in greater statistical power because of larger sample sizes, which could result in more effective marsh bird conservation.

To illustrate the cumulative advantages of reducing point count duration, consider that typically at least $\sim 2500$ 15-min marsh bird point counts are conducted at $\sim 1250$ points in $\sim 500$ wetlands annually by various organizations throughout the Great LakesSt. Lawrence region (Burton et al. 2008, Tozer 2013, 2016, Uzarski et al. 2017). By conducting 10-min instead of 15-min point counts across the region, approximately $12,500 \mathrm{~min}$ will be available for sampling new points. Assuming $25-75 \%$ of the saved time would be spent traveling, an additional $\sim 150-460$ new points could be surveyed at $\sim 70-200$ new wetlands. Based on total estimated survey costs per wetland (US\$1395 [2007 currency]; Meixler 2008), it might require $\sim$ US\$112,000-331,000 (estimated in 2017 currency) to survey these additional points using 15-min counts. By using 10-min instead of 15-min point counts, one essentially gains, at almost no additional cost, a $\sim 12-38 \%$ increase in sample size and associated statistical power in exchange for small reductions in detection probabilities for some species. For instance, the largest significant reduction in detection that we observed went from 0.75 during $\mathrm{P}_{1} \mathrm{BP}_{2}$ for Least Bittern down to 0.60 during $\mathrm{P}_{1} \mathrm{~B}$, whereas the smallest significant reduction went from 0.59 during $\mathrm{P}_{1} \mathrm{BP}_{2}$ for Virginia Rail down to 0.50 during $\mathrm{P}_{1} \mathrm{~B}$.

The multinomial $N$-mixture models with Poisson distributions that we used to estimate abundance and detection probability for some of the species did not fit adequately according to FreemanTukey fit statistics. Nonetheless, we used these apparently poorly fitting models for inference because predicted abundance and detection probability estimates were similar to previous estimates based on part of the same dataset using different methods (Tozer 2013, 2016, Tozer et al. 2016), suggesting that the models did fit adequately. We note that we included in the models a suite of covariates known to influence detection, suggesting that our use of the models to estimate differences in detection may not have been unduly influenced by apparent lack of fit (Kéry and Royle 2016).

We included a number of covariates in our statistical models, and found they influenced abundance and detection in most species, although the magnitude and direction of the influence varied considerably. This was expected given that abundance and detection in different species of marsh breeding birds respond in diverse ways to the covariates we considered (e.g., Tozer 2013, Tozer et al. 2016). For many species, detection significantly decreased as the season progressed, and as the number of hours to sunset or since sunrise increased. This was likely a result in most species of reduced activity and vocalization associated with completion of breeding and differences in activity levels as the day progressed, respectively. For half the species, detection was significantly higher during morning compared to evening, perhaps also because of differences in activity levels in most species. Although it is worth noting that the influence of morning versus evening on detection was much less among broadcast species and American Bittern. Detection of about one-third of these species was significantly higher during morning (Common Gallinule, Pied-billed Grebe), significantly higher during evening (American Bittern, Sora, Virginia Rail), or showed no significant difference (American Coot, Least Bittern), which supports the use of morning as well as evening surveys in monitoring programs targeting elusive marsh bird species (e.g., Tozer 2013, 2016, Uzarski et al. 2017). We also found that detection in many of the species was significantly higher for the MMP compared to the CWMP, the reasons for which are unclear, but perhaps related to differences in species abundances and sampling locations. The MMP targets Great Lakes coastal and inland wetlands in the southern portion of the Great Lakes basin, whereas the CWMP randomly samples Great Lakes coastal wetlands throughout the entire Great Lakes basin. Higher abundances of some species at inland wetlands compared to coastal wetlands may have increased detection for the MMP (Tozer 2013). Finally, we noted for half the species that abundance decreased over the years of the study, a finding that matches the results of others using part of the same dataset (Timmermans et al. 2008, Tozer 2013, 2016). This highlights the need investigated here to ensure that long-term, broad-scale monitoring programs maintain data continuity, including the ability to evaluate potential changes in detection, so statistically robust estimates are possible across many years of data collection. Robust long-term information will ultimately result in more effective conservation of declining species.

\section{CONCLUSION}

Prior to development of the standardized marsh bird protocol, some regional monitoring programs used point counts with call broadcasts during the first 5 min of 10-min counts, and have since used 15-min counts to ensure consistency in data across years and programs. However, the influence of timing of broadcasts within point counts has rarely been assessed. For six broadcast species and American Bittern, we found no significant difference in detection during $\mathrm{P}_{1} \mathrm{~B}$ compared to $\mathrm{BP}_{2}$, and no significant difference in detection in four of these seven species during $\mathrm{P}_{1}$ compared to $\mathrm{P}_{2}$. We did find significant but small differences in detection in 7 of the 14 species during $\mathrm{P}_{1} \mathrm{~B}$ compared to $\mathrm{P}_{1} \mathrm{BP}_{2}$. We conclude, (1) timing of broadcasts should not cause bias during analysis based on counts from entire 10-min surveys, (2) $\mathrm{P}_{1} \mathrm{~B}$ should be favored over $\mathrm{BP}_{2}$ because the same amount of effort avoids broadcast bias in all of the broadcast species, and (3) 10min surveys should be favored over 15-min surveys because modest gains in detection in some species does not warrant the additional effort. Saved effort could be invested in sampling more points, where possible, with an associated increase in statistical power and influence on conservation actions. We recommend point counts consisting of $5 \mathrm{~min}$ of passive observation followed by broadcasts, consistent with the standardized marsh bird protocol (Conway 2011), for surveying marsh breeding birds.

Responses to this article can be read online at: http://www.ace-eco.org/issues/responses.php/1063 


\section{Acknowledgments:}

We are very grateful for the dedication of hundreds of volunteer MMP participants, whose collective effort contributed a substantial portion of the large number of point counts analyzed in this study. We are also grateful for the coordination and promotion of the Great Lakes and Québec MMPs by Kathy Jones, Andrew Coughlan, and a large team of regional coordinators throughout the Great Lakes basin; and for past coordination of the programs by Russ Weeber, Steve Timmermans, and Ryan Archer in the Great Lakes, and Catherine Poussart in Québec. We extend a debt of gratitude to hundreds of landowners who granted access to private property. Bird Studies Canada is grateful for the support of its MMPs by the Government of Canada through the federal Department of the Environment, Brant Waterways Foundation, Ducks Unlimited Canada, Great Lakes Commission, Great Lakes Protection Fund, Great Lakes Restoration Initiative, Great Lakes Sustainability Fund, Great Lakes United, Government of Ontario, John and Pat McCutcheon Charitable Foundation, Kenneth M. Molson Foundation, National Audubon Society, Ontario Eastern Habitat Joint Venture, Ontario Trillium Foundation, Service Canada Summer Jobs Program, Science Horizons Program, TD Friends of the Environment Foundation, United States Environmental Protection Agency, Wetland Habitat Fund, and Wildlife Habitat Canada. We are grateful for the generous support of the CWMP by the Great Lakes National Program Office of the U.S. Environmental Protection Agency, under grant number GL-00E00612-0. Although the research described in this work has been partly funded by the U.S. Environmental Protection Agency, it has not been subjected to the agency's required peer and policy review and therefore does not necessarily reflect the views of the agency and no official endorsement should be inferred. The project was supported by Bird Studies Canada's Long Point Waterfowl and Wetlands Research Program, S. C. Johnson, The Bluff's Hunting Club, and the Great Lakes Restoration Initiative. And finally, we thank Ryan Norris, Erik Blomberg, and two anonymous reviewers for improving the manuscript.

\section{LITERATURE CITED}

Bird Studies Canada. 2009a. Marsh Monitoring Program participant's handbook for surveying marsh birds. Revised 2008. Bird Studies Canada in Cooperation with Environment Canada and the U.S. Environmental Protection Agency, Port Rowan, Ontario, Canada.

Bird Studies Canada. 2009b. Québec Marsh Monitoring Program training kit and instructions for surveying marsh birds and their habitats. 2008 edition. Bird Studies Canada in Cooperation with Environment Canada, Port Rowan, Ontario, Canada.

Burton, T. M., J. C. Brazner, J. J. H. Ciborowski, G. P. Grabas, J. Hummer, J. Schneider, and D. G. Uzarski, editors. 2008. Great Lakes Coastal Wetlands Monitoring Plan. Developed by the Great Lakes Coastal Wetlands Consortium, a project of the Great Lakes Commission, Ann Arbor, Michigan, USA. [online] URL: http:// www.greatlakeswetlands.org/docs/Publications/Great-Lakes-CoastalWetlands-Monitoring-Plan_FINAL.PDF

Conway, C. J. 2011. Standardized North American marsh bird monitoring protocol. Waterbirds 34:319-346. http://dx.doi. org/10.1675/063.034.0307
Conway, C. J., and J. P. Gibbs. 2005. Effectiveness of call-broadcast surveys for monitoring marsh birds. Auk 122:26-35. http://dx.doi. org/10.1642/0004-8038(2005)122[0026:EOCSFM]2.0.CO;2

Conway, C. J., and J. P. Gibbs. 2011. Summary of intrinsic and extrinsic factors affecting detection probability of marsh birds. Wetlands 31:403-411. http://dx.doi.org/10.1007/s13157-011-0155$\mathrm{x}$

Conway, C. J., and M. E. Seamfans. 2016. National Wildlife Refuge system protocol framework for the inventory and monitoring of secretive marsh birds. Inventory and Monitoring, National Wildlife Refuge System, U.S. Fish and Wildlife Service, Fort Collins, Colorado, USA. [online] URL: http://ecos.fws.gov/ServCatFiles/ reference/holding/53291

Correll, M. D., W. A. Wiest, T. P. Hodgman, W. G. Shriver, C. S. Elphick, B. J. McGill, K. M. O'Brien, and B. J. Olsen. 2017. Predictors of specialist avifaunal decline in coastal marshes. Conservation Biology 31:172-182. http://dx.doi.org/10.1111/ cobi.12797

Dénes, F. V., L. F. Silveira, and S. R. Beissinger. 2015. Estimating abundance of unmarked animal populations: accounting for imperfect detection and other sources of zero inflation. Methods in Ecology and Evolution 6:543-556. http://dx.doi.

org/10.1111/2041-210X.12333

DesRochers, D. W., H. K. W. Gee, and J. W. Reed. 2008. Response of Hawaiian Moorhens to broadcast of conspecific calls and a comparison with other methods. Journal of Field Ornithology 79:448-457. http://dx.doi.org/10.1111/j.1557-9263.2008.00190.x

Environment Canada. 2014. North American Breeding Bird Survey - Canadian Trends Website, Data-version 2012. Environment Canada, Gatineau, Québec, Canada.

Fiske, I., and R. Chandler. 2017. Overview of Unmarked: an $R$ package for the analysis of data from unmarked animals. $\mathrm{R}$ Foundation for Statistical Computing, Vienna, Austria. [online] URL: http://cran.r-project.org/web/packages/unmarked/vignettes/ unmarked.pdf

Fiske, I., R. Chandler, D. Miller, A. Royle, and M. Kéry. 2017. Package unmarked. R Foundation for Statistical Computing, Vienna, Austria. [online] URL: http://cran.r-project.org/web/ packages/unmarked/unmarked.pdf

Grabas, G. P., T. L. Crewe, and S. T. A. Timmermans. 2008. Bird community indicators. Pages 116-142 in T. M. Burton, J. C. Brazner, J. J. H. Ciborowski, G. P. Grabas, J. Hummer, J. Schneider, and D. G. Uzarski, editors. Great Lakes Coastal Wetlands Monitoring Plan. Developed by the Great Lakes Coastal Wetlands Consortium, a project of the Great Lakes Commission, Ann Arbor, Michigan, USA. [online] URL: http://www.greatlakeswetlands.org/docs/ Publications/Great-Lakes-Coastal-Wetlands-Monitoring-Plan_FINAL. PDF

Hanowski, J. M., N. P. Danz, R. W. Howe, R. R. Regal, and G. J. Niemi. 2007. Considerations for monitoring breeding birds in Great Lakes coastal wetlands. Journal of Great Lakes Research 33:245-252. http://dx.doi.org/10.3394/0380-1330(2007)33[245:CFMBBI] 2.0.CO;2

Kéry, M., and J. A. Royle. 2016. Applied hierarchical modeling in ecology: analysis of distribution, abundance and species richness in $R$ and BUGS, Vol. 1. Academic, Amsterdam, The Netherlands. 
Lor, S., and R. A. Malecki. 2002. Call-response surveys to monitor marsh bird population trends. Wildlife Society Bulletin 30:1195-1201.

Lowther, P. E., A. F. Poole, J. P. Gibbs, S. M. Melvin, and F. A. Reid. 2009. American Bittern (Botaurus lentiginosus). In P. G. Rodewald, editor. The birds of North America. Cornell Lab of Ornithology, Ithaca, New York, USA. http://dx.doi.org/10.2173/ bna. 18

MacKenzie, D. I., J. D. Nichols, J. E. Hines, M. G. Knutson, and A. B. Franklin. 2003. Estimating site occupancy, colonization, and local extinction when a species is detected imperfectly. Ecology 84:2200-2207. http://dx.doi.org/10.1890/02-3090

Meixler, M. 2008. Cost analysis for sampling of Great Lakes coastal wetlands. Pages 181-200 in T. M. Burton, J. C. Brazner, J. J. H. Ciborowski, G. P. Grabas, J. Hummer, J. Schneider, and D. G. Uzarski, editors. Great Lakes Coastal Wetlands Monitoring Plan Developed by the Great Lakes Coastal Wetlands Consortium, a project of the Great Lakes Commission, Ann Arbor, Michigan, USA. [online] URL: http://www.greatlakeswetlands. org/docs/Publications/Great-Lakes-Coastal-Wetlands-MonitoringPlan_FINAL.PDF

R Core Team. 2012. R: A language and environment for statistical computing. R Foundation for Statistical Computing, Vienna, Austria. [online] URL: http://www.R-project.org

Royle, J. A. 2004a. Generalized estimators of avian abundance from count survey data. Animal Biodiversity and Conservation 27:375-386.

Royle, J. A. 2004b. $N$-mixture models for estimating population size from spatially replicated counts. Biometrics 60:108-115. http://dx.doi.org/10.1111/j.0006-341X.2004.00142.x

Sauer, J. R., J. E. Hines, J. E. Fallow, K. L. Pardieck, D. J. Ziolkowski Jr., and W. A. Link. 2014. The North American Breeding Bird Survey, results and analysis 1966-2013. Version 01.30.2015. U.S. Geological Survey, Patuxent Wildlife Research Center, Laurel, Maryland, USA.

Schuster, R., and P. Arcese. 2013. Using bird species community occurrence to prioritize forests for old growth restoration. Ecography 36:499-507. http://dx.doi.org/10.1111/j.1600-0587.2012.07681. $\mathrm{x}$

Seamans, M., J. Wheeler, K. Koch, T. Cooper, C. Conway, C. Dwyer, and G. Shriver. 2013. Monitoring marsh birds to inform sound conservation and management decisions at multiple spatial scales: briefings and recommendations one year after the 2011 marsh bird summit. Waterbird Conservation for the Americas, U. S. Fish and Wildlife Service, Falls Church, Virginia, USA. [online] URL: https:/griffingroups.com/file/view/12099/monitoring-marshbirdsto-inform-sound-conservation-and-management-decisions-at-multiplescales
Steidl, R. J., C. J. Conway, and A. R. Litt. 2013. Power to detect trends in abundance of secretive marsh birds, effects of species traits and sampling effort. Journal of Wildlife Management 77:445-453. http://dx.doi.org/10.1002/jwmg.505

Timmermans, S. T. A., S. S. Badzinski, and J. W. Ingram. 2008. Associations between breeding marsh bird abundances and Great Lakes hydrology. Journal of Great Lakes Research 34:351-364. http://dx.doi.org/10.3394/0380-1330(2008)34[351:ABBMBA]2.0. $\mathrm{CO} ; 2$

Tozer, D. C. 2013. The Great Lakes Marsh Monitoring Program 1995-2012: 18 years of surveying birds and frogs as indicators of ecosystem health. Bird Studies Canada, Port Rowan, Ontario, Canada. [online] URL: http://www.birdscanada.org/download/ GLMMPreport.pdf

Tozer, D. C. 2016. Marsh bird occupancy dynamics, trends, and conservation in the southern Great Lakes basin: 1996 to 2013. Journal of Great Lakes Research 42:136-145. http://dx.doi. org/10.1016/j.jglr.2015.10.015

Tozer, D. C., K. L. Drake, C. M. Falconer. 2016. Modeling detection probability to improve marsh bird surveys in southern Canada and the Great Lakes states. Avian Conservation and Ecology 11:3. http://dx.doi.org/10.5751/ACE-00875-110203

Uzarski, D. G., V. J. Brady, M. J. Cooper, D. A. Wilcox, D. A. Albert, R. P. Axler, P. Bostwick, T. N. Brown, J. J. H. Ciborowski, N. P. Danz, J. P. Gathman, T. M. Gehring, G. P. Grabas, A. Garwood, R. W. Howe, L. B. Johnson, G. A. Lamberti, A. H. Moerke, B. A. Murry, G. J. Niemi, C. J. Norment, C. R. Ruetz III, A. D. Steinman, D. C. Tozer, R. Wheeler, T. K. O'Donnell, and J. P. Schneider. 2017. Standardized measures of coastal wetland condition: implementation at a Laurentian Great Lakes basin-wide scale. Wetlands 37:15-32. http://dx.doi.org/10.1007/ s13157-016-0835-7

Wiest, W. A., M. D. Correll, B. J. Olsen, C. S. Elphick, T. P. Hodgman, D. R. Curson, and W. G. Shriver. 2016. Population estimates for tidal marsh birds of high conservation concern in the northeastern USA from a design-based survey. Condor 118:274-288. http://dx.doi.org/10.1650/CONDOR-15-30.1
Editor-in-Chief: Ryan Norris Subject Editor: Erik Blomberg
Sponsored by the Society of Canadian Ornithologists and Bird Studies Canada Parrainée par la Société des ornithologistes du Canada et Études d'oiseaux Canada

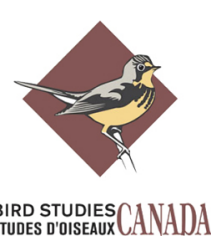

